Artigo com copyright pertencente à revista em que foi publicado.

Pode ser obtido nas plataformas B-On ou Science Direct ou através da página web da revista.

European Journal of Agronomy 28 (4) (2 008 ) 551-558

doi:10.1016/j.eja.2007.12.006

\title{
The yield pattern considering the distance to flow accumulation lines
}

J.R.Marques da Silva;L.L.Silva

Rural Engineering Department, Évora University, Apartado 94, 7002-554 Évora, Portugal; email: jmsilva@uevora.pt; 1lsilva@uevora.pt

\begin{abstract}
Precision agriculture techniques imply a spatial management of fields and to do so a good understanding of the spatial and temporal variability of yield is needed. Average yield data from seven irrigated maize fields were used to study the yield pattern considering the distance of plants to flow accumulation lines. It was found that there is a significant correlation between average yield and distance to flow accumulation lines (DFL). This correlation is best represented by a polynomial function. The most common shape of the yield pattern curve considering the distance to flow accumulation lines shows that there is an increase in average yield with DFL from 0 to $12.5-17.5 \mathrm{~m}$. Near the flow lines the average yield presents lower values due to drainage problems causing plant growth problems. It was also observed higher yield variability near the flow lines. For higher distances from the flow lines there is a continuous decrease in average yield due to less water availability and other variations of soil properties.
\end{abstract}

(C) 2008 Elsevier B.V. All rights reserved. 